\title{
Health Significance of Fat Quality in the Diet
}

\author{
Joyce A. Nettleton ${ }^{a}$ Salvador Villalpando ${ }^{b}$ Roberta Soares Lara Cassani ${ }^{c}$ \\ Ibrahim Elmadfad \\ ${ }^{a}$ ScienceVoice Consulting, Denver, Colo., USA; ${ }^{b}$ Center for Research in Nutrition and Health, National Institute of \\ Public Health, Cuernavaca, Mexico; ' Nutrition Institute and Laboratory of Investigation in Metabolism and Diabetes, \\ Medicine College, University of São Paulo, Ribeirão Preto, Brazil; ${ }^{d}$ International Union of Nutritional Sciences, \\ Institute of Nutritional Sciences, University of Vienna, Vienna, Austria
}

\section{Key Words}

Cardiovascular disease $\cdot$ Chronic diseases - Dietary fat quality · Fat teaching individuals and families to modify their food intake patterns and control the major risk factors for chronic disease.

Copyright $\odot 2013$ S. Karger AG, Basel

\begin{abstract}
This paper summarizes three presentations on the global and Latin American perspectives on the health significance of fat quality in the diet given at the 16th Congress of the Society of Latin American Nutrition in Havana, Cuba, November 11-16, 2012. Dietary fat quality contributes to the risk of the leading chronic diseases and is more important than fat quantity in reducing the risk of chronic disease mortality, especially from cardiovascular disease (CVD). In many countries, the consumption of saturated fats exceeds the recommended limit of $10 \%$ energy (\%E) and intakes of polyunsaturated fats (PUFAs) are often below the recommended range of $6-11 \%$ E. Consumption of long-chain $\omega-3$ PUFAs is especially low. In many Latin American countries, high consumption of carbohydrates, especially sugars, contributes to obesity, diabetes, hypertension and CVD, while intakes of total fat and PUFAs may be low. Thus, dietary fat recommendations must consider the dietary fat patterns of each country. Nutrition counseling can be effective in
\end{abstract}

\section{Introduction}

The 16th Congress of the Society of Latin American Nutrition was held in Havana, Cuba, November 11-16, 2012. The International Union of Nutrition Sciences and the International Experts Movement (http://theiem.org/ index.html) with sponsorship from Unilever Research and Development, The Netherlands, hosted a symposium on the 'Health Significance of Fat Quality in the Diet: Latin American and Global Perspectives', with presentations by Ibrahim Elmadfa (President of the International Union of Nutritional Sciences and Professor of the University of Vienna); Salvador Villalpando (National Public Health Institute, Mexico) and Roberta Cassani (Laboratory of Investigation in Metabolism and Diabetes, Medicine College, University of São Paulo, Ribeirão Preto, Brazil). This paper summarizes their presentations and each speaker's general conclusions. It highlights the com-

\begin{tabular}{ll}
\hline KARGER & $\begin{array}{l}\text { ○ 2013 S. Karger AG, Basel } \\
\text { 0250-6807/13/0632-0096 } \$ 38.00 / 0 \quad \text { Karger }\end{array}$ \\
E-Mail karger@karger.com & $\begin{array}{l}\text { This is an Open Access article licensed under the terms of the } \\
\text { www.karger.com/anm }\end{array}$ \\
& $\begin{array}{l}\text { Creative Commons Attribution-NonCommercial 3.0 Un- } \\
\text { ported license (CC BY-NC) (www.karger.com/OA-license), } \\
\text { applicable to the online version of the article only. Distribu- } \\
\text { tion permitted for non-commercial purposes only. }\end{array}$
\end{tabular}

Joyce A. Nettleton

ScienceVoice Consulting 2931 Race Street

Denver, CO 80205 (USA)

E-Mail sciencevoice1@gmail.com 


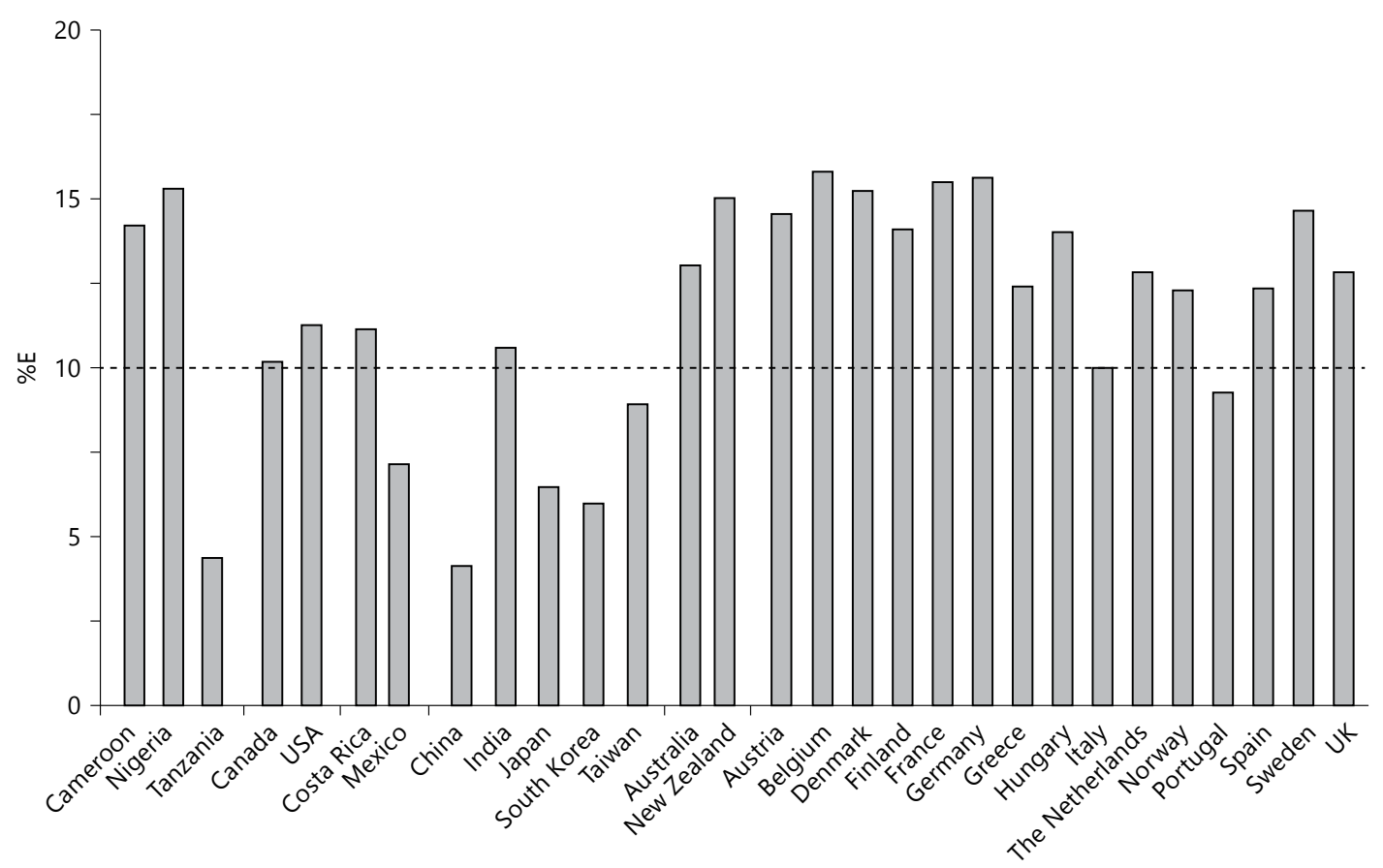

Fig. 1. Saturated fatty acid intake in selected countries. The horizontal dotted line indicates the upper limit of the recommended intake.

monalities of dietary fat and fatty acid intakes globally, their associations with major chronic diseases and health conditions, the differences in fat intakes among world regions and Latin American countries, and examples of region-specific approaches to individual dietary change for improved health.

\section{Global Intakes and Requirements for Fat and Fatty Acids}

Dietary fat is not only a concentrated source of energy, it carries fat-soluble vitamins and other nutritive substances, provides essential fatty acids and serves physiological functions in the body.

Certain essential polyunsaturated fatty acids (PUFAs) cannot be synthesized by humans or converted from precursors in sufficient amounts to meet nutritional needs and, therefore, must be consumed in the diet [1]. Fatty acids are an integral part of the cell membrane [2] where they are involved in signal transduction [3]. Some PUFAs are precursors for the synthesis of eicosanoids and other lipid mediators [4] that regulate the immune and vascular systems. PUFAs of both the $\omega-6(n-6)$ and $\omega-3(n-3)$ families favorably affect blood lipids and other factors involved in protecting cardiovascular health $[5,6]$. Because the effects of these two PUFA families and the individual fatty acids within them differ substantially and may even be contradictory, the consumption of and dietary recommendations for n-6 and n-3 PUFAs are considered separately.

Fat consumption contributes to the most prevalent chronic diseases in the world - cardiovascular disease (CVD), diabetes, overweight and obesity, for example [7]. Recognition that dietary fat quality is more important than the total quantity consumed has encouraged health authorities around the world to examine the amounts and types of fat consumed in their respective countries. Results vary widely by country, with several Western countries having higher than recommended intakes of total fat and most countries in Europe, America, parts of Africa, Asia, Australia and New Zealand consuming more than $10 \%$ energy (\%E) from saturated fatty acids (fig. 1 ). These countries are more likely to have PUFA intakes below the range of $6-11 \%$ and suboptimal intakes of $n-3$ PUFAs, especially the long-chain (LC) n-3 fatty acids eicosapentaenoic acid (EPA) and docosahexaenoic acid (DHA) [8]. The variability in fat and fatty acid intakes in various continents is illustrated in table 1 [9]. 
Table 1. Ranges of $\% \mathrm{E}$ from total fat and fatty acid (FA) classes by continent [adapted from ref. 9]

\begin{tabular}{llrrl}
\hline Continent & Total fat & \multicolumn{1}{l}{ SFA } & MUFA & PUFA \\
\hline Africa (2, 3) & $13.1-50.7$ & $4.1-25.4$ & $4.7-16.4$ & $4.0-5.9$ \\
America (4) & $25.7-37.2$ & $7.4-12.2$ & $7.2-14.3$ & $4.4-7.1$ \\
Asia (5) & $11.1-35.6$ & $3.1-10.6$ & $3.5-12.6$ & $3.3-11.3$ \\
Australia (2) & $32.5-35.0$ & $12.7-15.0$ & $11.8-12.0$ & 5.0 \\
Europe (14) & $28.5-46.2$ & $8.9-16.5$ & $10.9-22.3$ & $4.0-8.5$ \\
\hline
\end{tabular}

The number of countries are given in parentheses. SFA = Saturated FA; MUFA = monounsaturated FA.

Most trans-fatty acids in foods are formed during the partial hydrogenation of unsaturated fatty acids in the manufacture of solid fats and were later shown to markedly increase the risk of CVD by raising total cholesterol and low-density lipoprotein levels, reducing high-density lipoprotein concentrations and adversely affecting the physical characteristics of cell membranes [10]. Efforts to reduce industrially produced trans-fatty acids from the food supply in the US, European Union and Latin America have made some progress $[11,12]$, but intakes remain significantly above recommended maximum levels $(1 \% \mathrm{E})$ in many lower income countries [13].

A consistent recommendation to reduce the risk of coronary heart disease by improving the quality of fat consumed is the substitution of saturated fatty acids by PUFAs $[14,15]$. A review of prospective cohort studies reported that replacing saturated fats with PUFAs rather than monounsaturates of carbohydrates reduced the risk of coronary deaths by $25 \%$ [16]. Similarly, a meta-analysis of randomized controlled trials reported a $10 \%$ reduction in the coronary heart disease risk for each $5 \% \mathrm{E}$ of increased PUFA substituted for saturated fat [17].

Many national and international health organizations have devised recommendations for fat and fatty acid consumption that facilitate energy balance, meet essential fatty acid requirements and reduce the risk of CVD, while limiting the consumption of potentially detrimental fatty acids. The Food and Agriculture Organization and the World Health Organization published the recommendations of its Expert Consultation on Fats and Fatty Acids for adults, as summarized in table 2 [18].

Recommendations for the consumption of $n-3$ PUFAs vary with age, reproductive and health status and the type of n-3 PUFA. There are separate recommendations for pregnant and lactating women [19], children [18], and individuals with and without CVD [20] and for $\mathrm{n}-3$ PUFAs from plant and animal sources. Vegetable sourc-
Table 2. Dietary intakes recommended by the Food and Agriculture Organization and the World Health Organization for total fat and fatty acids (FAs) for adults [18]

\begin{tabular}{ll}
\hline Fat/FA & Intake range \\
\hline Total fat $^{\mathrm{a}}$ & $15-35 \% \mathrm{E}$ \\
Saturated FA (upper limit) $^{\text {Monounsaturated FA }}$ & $10 \% \mathrm{E}$ \\
Total PUFA & by difference \\
$\mathrm{n}-6$ & $6-11 \% \mathrm{E}$ \\
$\mathrm{n}-3^{\mathrm{b}}$ & $2.5-9 \% \mathrm{E}$ \\
$\mathrm{ALA}$ & $0.5-2 \% \mathrm{E}$ \\
$\mathrm{EPA}+$ DHA & $\geq 0.5 \% \mathrm{E}$ \\
Trans-FA (upper limit) & $0.25-2 \mathrm{~g} /$ day \\
\hline
\end{tabular}

a Upper and lower limits for men and women.

${ }^{\mathrm{b}}$ Includes ALA + EPA + DHA.

es, such as flax seed and oil, walnuts, chia seeds, perilla, canola and soybean oils, contain only a-linolenic acid (ALA). The n-3 LC-PUFAs, mainly EPA and DHA, occur primarily in fish and shellfish, especially in fatty ocean fish. Varying amounts of DHA also occur in egg yolk and lean meat, with levels dependent upon the diet of the animal [21]. ALA has modest effects on cardiovascular health, but cannot substitute for DHA required for brain structure and function. Pregnant and lactating women are advised to consume at least $200 \mathrm{mg}$ of DHA per day because the conversion of ALA to n-3 LC-PUFAs is insufficient to meet the fetus, and infant's need for DHA [19]. A summary of some recommendations for n-3 LCPUFA intakes is shown in table 3.

In summary, total fat and fatty acid intakes vary widely by country. Comparatively low fat intakes are found mainly in eastern Asia and some low-income African countries. Many countries following a Western diet con- 
Table 3. Selected recommended intakes of EPA + DHA for various adult groups

\begin{tabular}{lcl}
\hline Target group & EPA + DHA, mg/day & Fish intake \\
\hline Adults & 250 & $100 \mathrm{~g}$ fatty fish/week [20] \\
Primary prevention of CVD & $250-500$ & $100-200 \mathrm{~g}$ fatty fish/week [20] \\
Secondary prevention & 1,000 & fatty fish or supplements [20] \\
Patients with hypertriglyceridemia & $>3,000$ & fatty fish + supplements under physician's care [20] \\
Pregnant and lactating women & $200 \mathrm{mg}$ of DHA & $\begin{array}{l}100-200 \mathrm{~g} \text { fatty fish/week, 1-2 g/day of n-3 LC PUFA are } \\
\text { without significant adverse effects [19] }\end{array}$ \\
\hline
\end{tabular}

sume more than the recommended amount of saturated fat and less than the recommended levels of PUFAs, especially those of the $n-3$ family. Most also have high rates of CVD and mortality along with increasing rates of obesity and diabetes. Changes in dietary fat intakes that substitute PUFAs for saturated fatty acids have the potential to reduce CVD mortality significantly. The same holds for increasing the consumption of n-3 LC-PUFAs.

\section{Fat and Fatty Acid Intakes in Latin America and Mexico}

High fat intakes contribute to greater total energy consumption and have been associated with a higher risk of CVD and obesity [22], although some dispute this conclusion [23]. In CVD, it is mainly poor dietary fat quality, especially the consumption of saturated and trans-fat, that affects disease risk [24, 25]. In Latin American countries, noncommunicable diseases account for $69 \%$ of deaths, with CVD accounting for $31 \%$ of all such deaths $[26,27]$. Death rates from CVD are decreasing in a few countries, e.g. Argentina, Brazil and Chile, but increasing in others, e.g. Mexico and Venezuela [27]. Cardiometabolic diseases - hypertension, metabolic syndrome, type 2 diabetes, renal failure and heart failure - have been described as 'epidemic' in Latin America [28], with abdominal obesity singled out as the most important risk factor. Most Latin American countries have high prevalences of overweight and obesity that are predicted to affect $50 \%$ of males and $60 \%$ of females by the year 2030 , Argentina excepted [29]. It has also been noted that obesity is becoming a disease of the poor, which highlights the social, cultural and economic factors that contribute to it $[29,30]$.

Premature mortality from diabetes is also high in several Latin American countries, such as Venezuela and Mexico, but is markedly lower in others, including Argentina and Chile. Such variability in the health status

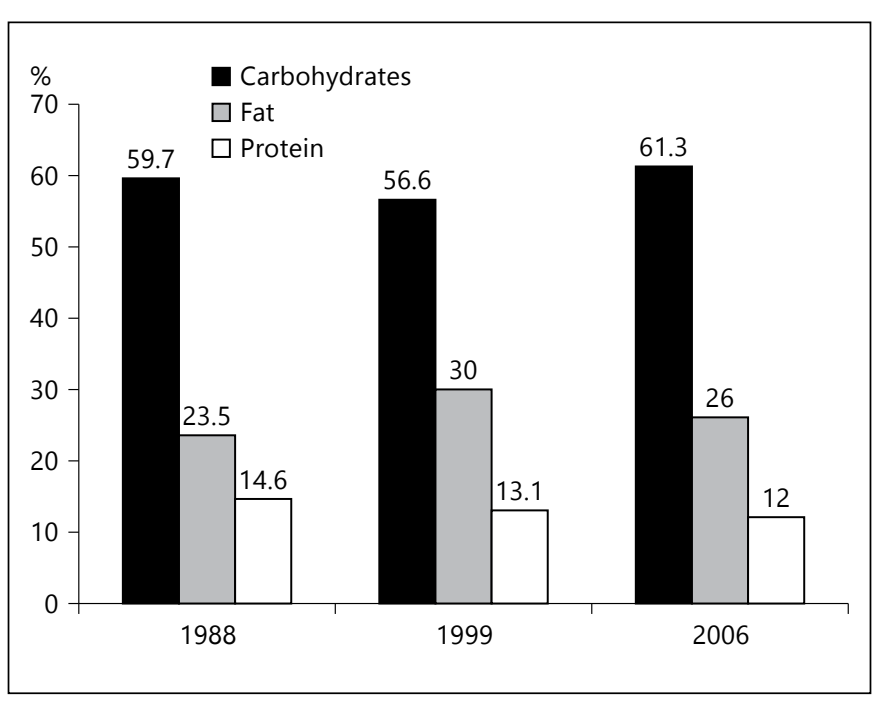

Fig. 2. Distribution of carbohydrate, fat and protein intakes in Mexico, 1988-2006 [Villalpando, pers. commun., 2013].

[31] suggests that different approaches to dietary fat consumption will be required for individual countries to reduce their health risks. The question is 'Do current dietary fat recommendations address the main culprits in Latin American diets?'.

The World Health Organization recommends reducing fat intake to $20-35 \% \mathrm{E}$ to combat CVD, obesity, diabetes and other chronic diseases [18]. This recommendation appears appropriate for Europe and North America where fat intakes had reached $40 \% \mathrm{E}$. However, in most Latin American countries, fat intake is less than $30 \% \mathrm{E}$ (fig. 2) and carbohydrates may supply as much as $66 \% \mathrm{E}$ [29].

In Mexico, $40 \%$ of adults were classified as overweight and $30 \%$ as obese according to the 2006 National Health and Nutrition Survey (ENSANUT) [32]. Consumption of fat is approximately $23 \% \mathrm{E}$, with about $10 \% \mathrm{E}$ coming from 
saturated fats and $<0.5 \%$ from trans-fats. However, approximately $44 \%$ of adults consume more than $10 \% \mathrm{E}$ from saturated fat [33], with excessive intakes greatest among children and adolescents. These fat consumption data compare favorably with the US, where dietary and saturated fat contribute 33 and $11 \% \mathrm{E}$, while $33 \%$ of adults over the age of 20 are overweight and $35 \%$ obese [34, 35]. Consumption of PUFAs by adults is $3 \%$ for linoleic acid, with very low intakes of $n-3$ PUFAs $(0.02 \%), 85 \%$ of which come from ALA [33]. For Mexico and other Latin American countries with similar dietary fat patterns, total and trans-fat consumption are within the recommended ranges, but intakes of saturated fat exceed recommended levels, while PUFA intakes, especially those of n-3 PUFAs, are well below recommended amounts.

A major dietary concern in Mexico, certain other Latin American countries and elsewhere is the high intake of carbohydrates from sweetened beverages, sugary cereals and industrial snacks, which has been associated with overweight and obesity in Mexican school-age children [36]. Sweetened beverage consumption has also been linked to coronary heart disease [37], obesity and type 2 diabetes [38]. In the context of CVD, replacement of saturated fats by carbohydrates may be detrimental to blood lipid patterns, insulin resistance and obesity, especially if the replacement carbohydrates are low in fiber and have a high glycemic index $[39,40]$. Thus, replacement of saturated fats by polyunsaturated fats remains prudent advice $[14,15]$.

In summary, many Latin American countries have high rates of CVD, obesity/overweight and type 2 diabetes. Saturated fat intakes exceed recommended levels in many, but not all, Latin American countries. Total fat consumption is often within the recommended range and trans-fat intakes are low. PUFA intakes are also low, especially for n-3 PUFAs. Current fat recommendations for Western diets may overlook the primary issues in fatty acid intakes in many Latin American countries.

\section{Changing an Individual's Diet to Meet Recommendations while Considering Regional Variations: The Brazilian Example}

Noncommunicable diseases accounted for $72 \%$ of all deaths in Brazil in 2007, with the toll greatest among the poor [41]. CVD is the leading cause of death. Successful health policies have contributed to reductions in smoking and deaths from CVD and chronic respiratory diseases [41]. However, widespread, unhealthy, lifestyle habits, in-

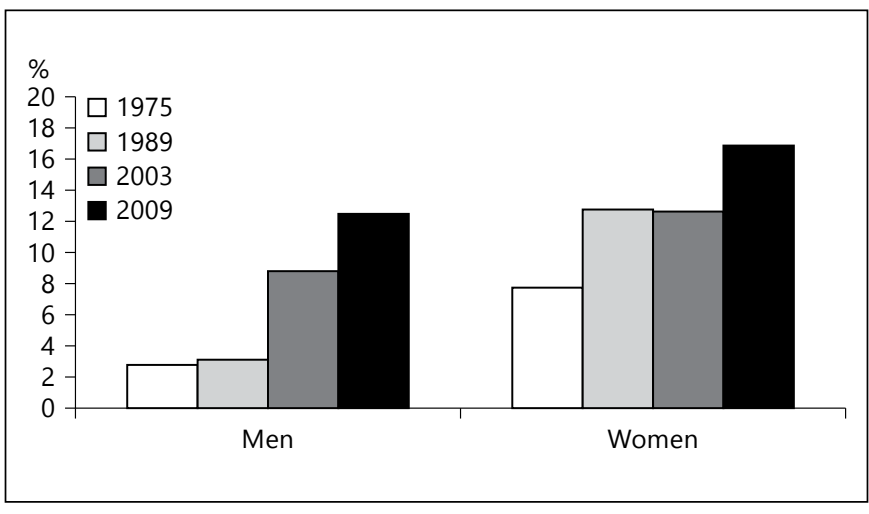

Fig. 3. Secular trends for obesity in Brazil from 1975 to 2009.

cluding smoking and low physical activity, contribute to the suboptimal health status. High prevalence rates were reported for overweight (43\%) and obesity (11\%), hypercholesterolemia (22\%), hypertension $(22 \%)$ and diabetes (5\%), as documented in a national survey in Brazil in 2006 and a study of Brazilian industrial workers in 2009 [42, 43]. Obesity rates increased in Brazil from 1975 to 2009 (fig. 3), especially among girls [44], suggesting that obesity among adolescents is a key target for prevention strategies. Like obesity, rates of diabetes and hypertension have increased $[41,45]$.

Food consumption patterns in Brazil are changing [46], with the gap between urban and rural areas disappearing [47]. All regions use rice and beans and regional dietary patterns associated with healthy eating remain important. Nutrient intakes are undergoing transition, with increased consumption of ready-to-eat and processed foods, soda and juices. A higher consumption of highly refined processed foods, sweetened beverages and solid fats plus a decline in the consumption of vegetables and skim milk contribute to the erosion of healthy eating habits and the increase in disease risk factors [48]. Increased consumption of meals and soft drinks away from home was associated with increased risk of overweight and obesity among men but not among women [49]. The high consumption of solid fats also contributes to intakes of saturated and trans-fats in excess of recommended amounts [48].

Successful strategies to help individuals reach recommended dietary intakes use anthropometric measures, dietary intake assessment and food consumption patterns to determine a person's nutritional status and food behaviors. The primary focus is to meet nutritional needs and prevent or control chronic disease risk factors through 
guided behavior change. In Brazil, nutritionists successfully use counseling to teach portion control, incorporate recommended food groups and introduce healthful recipes [50]. The counselors include patient and family activities to teach cooking techniques for healthy food preparation, introduce new recipes and stimulate the sensory appreciation of food. They prepare a nutritional intervention plan for each patient that retains the usual macronutrient distribution while increasing the quality and proportion of recommended foods. Using this approach, total \%E from fat was reported to remain similar to the pre-intervention period, but the $\% \mathrm{E}$ from saturated fat is reduced and the level of $\% \mathrm{E}$ from polyunsaturated fat, linoleic acid and ALA increased. Creating a relaxed and positive environment leads to greater compliance with suggested lifestyle modifications [50].

In summary, overweight and obesity have increased rapidly in Brazil, increasing the risk of hypertension and diabetes. Changing food consumption patterns with increased intakes of sweetened beverages, highly refined foods and solid fats have contributed to unhealthy eating patterns, excessive consumption of energy, saturated and trans-fats and increased the risk of several chronic diseases. Successful strategies for improving nutrient, fat and food intakes have been developed using patient-centered nutrition education, healthy guidelines and group participation in the preparation of healthy recipes.

\section{Acknowledgments}

Selected material from this paper was originally presented at the 16th Congress of the Society of Latin American Nutrition in Havana, Cuba, November 11-16, 2012. Financial assistance for this publication was provided by Unilever, The Netherlands. Authors declare no conflicts of interest.

\section{References}

1 Brenna JT, Lapillonne A: Background paper on fat and fatty acid requirements during pregnancy and lactation. Ann Nutr Metab 2009;55:97-122.

2 Mitchell DC: Progress in understanding the role of lipids in membrane protein folding. Biochim Biophys Acta 2012;1818:951956.

-3 Graber R, Sumida C, Nunez EA: Fatty acids and cell signal transduction. J Lipid Mediat Cell Signal 1994;9:91-116.

4 Funk CD: Prostaglandins and leukotrienes: advances in eicosanoid biology. Science 2001; 294:1871-1875

5 De Caterina R: $\mathrm{n}-3$ fatty acids in cardiovascular disease. N Engl J Med 2011;364:2439_ 2450.

6 Harris WS, Mozaffarian D, Rimm E, KrisEtherton P, Rudel LL, Appel LJ, Engler MM, Engler MB, Sacks F: Omega- 6 fatty acids and risk for cardiovascular disease: a science advisory from the American Heart Association Nutrition Subcommittee of the Council on Nutrition, Physical Activity, and Metabolism; Council on Cardiovascular Nursing; and Council on Epidemiology and Prevention. Circulation 2009;119:902-907.

-7 World Health Organization: Diet, nutrition and the prevention of chronic diseases. World Health Organ Tech Rep Ser 2003;916:i-viii, 1-149.

8 Elmadfa I, Kornsteiner M: Fats and fatty acid requirements for adults. Ann Nutr Metab 2009;55:56-75.

-9 Elmadfa I, Kornsteiner M: Dietary fat intake a global perspective. Ann Nutr Metab 2009; 54(suppl 1):8-14.
10 Ganguly R, Pierce GN: Trans fat involvement in cardiovascular disease. Mol Nutr Food Res 2012;56:1090-1096.

11 Doell D, Folmer D, Lee H, Honigfort M, Carberry S: Updated estimate of trans fat intake by the US population. Food Addit Contam Part A Chem Anal Control Expo Risk Assess 2012;29:861-874.

12 Stender S, Astrup A, Dyerberg J: A trans European Union difference in the decline in trans fatty acids in popular foods: a market basketinvestigation. BMJOpen 2012:e00859.

13 Monge-Rojas R, Colon-Ramos U, Jacoby E, Mozaffarian D: Voluntary reduction of transfattyacids in Latin America and the Caribbean: current situation. Rev Panam Salud Publica 2011;29:126-129.

14 Astrup A, Dyerberg J, Elwood P, Hermansen $\mathrm{K}, \mathrm{Hu}$ FB, Jakobsen MU, Kok FJ, Krauss RM, Lecerf JM, LeGrand P, Nestel P, Riserus U, Sanders T, Sinclair A, Stender S, Tholstrup T, Willett WC: The role of reducing intakes of saturated fat in the prevention of cardiovascular disease: where does the evidence stand in 2010? Am J Clin Nutr 2011;93:684-688.

-15 Pedersen JI, James PT, Brouwer IA, Clarke R, Elmadfa I, Katan MB, Kris-Etherton PM, Kromhout D, Margetts BM, Mensink RP, Norum KR, Rayner M, Uusitupa M: The importance of reducing SFA to limit CHD. Br J Nutr 2011;106:961-963.

16 Jakobsen MU, O’Reilly EJ, Heitmann BL, Pereira MA, Balter K, Fraser GE, Goldbourt U, Hallmans G, Knekt P, Liu S, Pietinen P, Spiegelman D, Stevens J, Virtamo J, Willett WC, Ascherio A: Major types of dietary fat and risk of coronary heart disease: a pooled analysis of 11 cohort studies. Am J Clin Nutr 2009;89:1425-1432.

17 Mozaffarian D, Micha R, Wallace S: Effects on coronary heart disease of increasing polyunsaturated fat in place of saturated fat: a systematic review and meta-analysis of randomized controlled trials. PLoS Med 2010;7:e1000252.

18 FAO/WHO: Joint Expert Consultation on Fats and Fatty Acids in Human Nutrition: Interim Summary of Conclusions and Dietary Recommendations on Total Fat and Fatty Acids. Geneva, World Health Organization, 2008, p 15.

19 Koletzko B, Cetin I, Brenna JT: Dietary fat intakes for pregnant and lactating women. $\mathrm{Br} \mathrm{J}$ Nutr 2007;98:873-877.

20 Kris-Etherton PM, Harris WS, Appel LJ: Fish consumption, fish oil, omega-3 fatty acids, and cardiovascular disease. Arterioscler Thromb Vasc Biol 2003;23:e20-e30.

21 Moghadasian MH: Advances in dietary enrichment with n-3 fatty acids. Crit Rev Food Sci Nutr 2008;48:402-410.

22 Bray GA, Paeratakul S, Popkin BM: Dietary fat and obesity: a review of animal, clinical and epidemiological studies. Physiol Behav 2004;83:549-555.

23 Willett WC, Leibel RL: Dietary fat is not a major determinant of body fat. Am J Med 2002;113(suppl 9B):47S-59S.

24 Micha R, Mozaffarian D: Saturated fat and cardiometabolic risk factors, coronary heart disease, stroke, and diabetes: A fresh look at the evidence. Lipids 2010;45:893-905.

25 Mozaffarian D, Katan MB, Ascherio A, Stampfer MJ, Willett WC: Trans fatty acids and cardiovascular disease. N Engl J Med 2006;354:1601-1613.
Health Significance of Fat Quality in the Diet 
26 Perel P, Casas JP, Ortiz Z, Miranda JJ: Noncommunicable diseases and injuries in Latin America and the Caribbean: time for action. PLoS Med 2006;3:e344.

27 Rodriguez T, Malvezzi M, Chatenoud L, Bosetti C, Levi F, Negri E, La Vecchia C: Trends in mortality from coronary heart and cerebrovascular diseases in the Americas: 1970-2000. Heart 2006;92:453-460.

28 Lopez-Jaramillo P, Lahera V, Lopez-Lopez J: Epidemic of cardiometabolic diseases: a Latin American point of view. Ther Adv Cardiovasc Dis 2011;5:119-131.

-29 Webber L, Kilpi F, Marsh T, Rtveladze K, Brown M, McPherson K: High rates of obesity and non-communicable diseases predicted across Latin America. PLoS One 2012; 7:e39589.

- 30 Albala C, Vio F, Kain J, Uauy R: Nutrition transition in Chile: determinants and consequences. Public Health Nutr 2002;5:123-128.

-31 Andrade F: Estimating diabetes and diabetesfree life expectancy in Mexico and seven major cities in Latin America and the Caribbean. Rev Panam Salud Publica 2009;26:9-16.

-32 Barquera S, Campos-Nonato I, HernandezBarrera L, Flores M, Durazo-Arvizu R, Kanter R, Rivera JA: Obesity and central adiposity in Mexican adults: results from the Mexican National Health and Nutrition Survey 2006. Salud Publica Mex 2009;51(suppl 4):S595S603.

-33 Ramirez-Silva I, Villalpando S, Moreno-Saracho JE, Bernal-Medina D: Fatty acids intake in the Mexican population. Results of the $\mathrm{Na}$ tional Nutrition Survey 2006. Nutr Metab (Lond) 2011;8:33-43.
34 National Center for Health Statistics: Health, United States, 2011: With Special Feature on Socioeconomic Status and Health. Hyattsville, National Center for Health Statistics, 2012, p 566.

35 Rhodes DG, Clemens JC, Goldman JD, LaComb RP, Moshfegh AJ: 2009-2010. What we eat in America, NHANES tables 1-36. http://www.Ars.Usda.Gov/services/docs. $\mathrm{Htm}$ ?Docid=18349.

36 Rodriguez-Ramirez S, Mundo-Rosas V, Garcia-Guerra A, Shamah-Levy T: Dietary patterns are associated with overweight and obesity in Mexican school-age children. Arch Latinoam Nutr 2011;61:270-278.

37 de Koning L, Malik VS, Kellogg MD, Rimm EB, Willett WC, Hu FB: Sweetened beverage consumption, incident coronary heart disease, and biomarkers of risk in men. Circulation 2012;125:1735-1741.

38 Hu FB, Malik VS: Sugar-sweetened beverages and risk of obesity and type 2 diabetes: epidemiologic evidence. Physiol Behav 2010; 100:47-54.

39 Siri-Tarino PW, Sun Q, Hu FB, Krauss RM: Saturatedfat, carbohydrate, and cardiovascular disease. Am J Clin Nutr 2010;91:502-509.

40 Jakobsen MU, Dethlefsen C, Joensen AM, Stegger J, Tjonneland A, Schmidt EB, Overvad $\mathrm{K}$ : Intake of carbohydrates compared with intake of saturated fatty acids and risk of myocardial infarction: importance of the glycemic index. Am J Clin Nutr 2010;91: 1764-1768.

41 Schmidt MI, Duncan BB, Azevedo e Silva G, Menezes AM, Monteiro CA, Barreto SM, Chor D, Menezes PR: Chronic non-communicable diseases in Brazil: burden and current challenges. Lancet 2011;377:1949-1961.

42 Cassani RS, Nobre F, Pazin Filho A, Schmidt A: Prevalence of cardiovascular risk factors in a population of Brazilian industry workers. Arq Bras Cardiol 2009;92:16-22.
43 Iser BP, Claro RM, de Moura EC, Malta DC, Morais Neto OL: Risk and protection factors for chronic non communicable diseases by telephone survey-VIGITEL-2009. Rev Bras Epidemiol 2011;14(suppl 1):90-102.

44 Barros EG, Pereira RA, Sichieri R, da Veiga GV: Variation of BMI and anthropometric indicators of abdominal obesity in Brazilian adolescents from public schools, 2003-2008. Public Health Nutr 2012;1-8.

45 Cassani RS, Nobre F, Pazin-Filho A, Schmidt A: Relationship between blood pressure and anthropometry in a cohort of Brazilian men: a cross-sectional study. Am J Hypertens 2009; 22:980-984.

46 Marchioni DM, Claro RM, Levy RB, Monteiro CA: Patterns of food acquisition in Brazilian households and associated factors: a population-based survey. Public Health Nutr 2011;14:1586-1592.

47 Nascimento S, Barbosa FS, Sichieri R, Pereira RA:Dietary availability patterns of the Brazilian macro-regions. Nutr J 2011;10:79-86.

-48 Pereira RA, Duffey KJ, Sichieri R, Popkin BM: Sources of excessive saturated fat, trans fat and sugar consumption in Brazil: an analysis of the first Brazilian nationwide individual dietary survey. Public Health Nutr 2012, pp 1-9.

49 Bezerra IN, Sichieri R: Eating out of home and obesity: a Brazilian nationwide survey. Public Health Nutr 2009;12:2037-2043.

50 Cassani RSL: O que é uma dieta saudável para prevençãoda doença cardiovascular: o papel dos nutrientes sobre lípides, sobrepeso, hipertensãoarterial e inflamação subclínica. Rev Soc Cardiol Estado de São Paulo 2012;22:9. 